\title{
Remarkable surface-enhanced Raman scattering of highly crystalline monolayer $\mathrm{Ti}_{3} \mathrm{C}_{2}$ nanosheets
}

\author{
Yuting $\mathrm{Ye}^{1 \dagger}$, Wencai $\mathrm{Yi}^{2 \dagger}$, Wei Liu ${ }^{1}$, Yun Zhou ${ }^{3}$, Hua Bai ${ }^{1}$, Junfang $\mathrm{Li}^{1}$ and Guangcheng $\mathrm{Xi}^{{ }^{*}}$
}

\begin{abstract}
As a powerful non-destructive and label-free detection technology, surface-enhanced Raman scattering (SERS) has been widely used in environmental-pollutant detection, biological-tissue sensing, molecular fingerprint analysis and so on. Different from the traditional SERS substrates represented by noble metals and semiconductors, herein, we report a new highly sensitive SERS substrate material with high stability, biocompatibility, and low cost, namely nucleusfree two-dimensional electron gas (2DEG) $\mathrm{Ti}_{3} \mathrm{C}_{2}$ monolayer nanosheets. The highly crystalline monolayer $\mathrm{Ti}_{3} \mathrm{C}_{2}$ nanosheets with clean surface are synthesized by an improved chemical exfoliation and microwave heating method. The unique structure of nucleus-free-2DEG in $\mathrm{Ti}_{3} \mathrm{C}_{2}$ monolayer provides an ideal transport channel without nuclear scattering, which makes the highly crystalline monolayer $\mathrm{Ti}_{3} \mathrm{C}_{2}$ nanosheets achieve a Raman enhanced factor of $3.82 \times 10^{8}$ and a $10^{-11}$ level detection limit for typical environmental pollutants such as azo dyes, trichlorophenol, and bisphenol A. Singlemolecule imaging is also realized on the surface of the $\mathrm{Ti}_{3} \mathrm{C}_{2}$ monolayers, which may be the first time that approximate single-molecule imaging has been achieved on a non-noblemetal SERS substrates. Preliminary toxicological experiments show that the cytotoxicity of this material is very low. Considering the facile synthesis, high biocompatibility, low cost and high chemical stability of carbide nanosheets, these $\mathrm{Ti}_{3} \mathrm{C}_{2}$ monolayer nanosheets show significant promise for the design and fabrication of flexible SERS substrates for the sensing of trace substances with ultrahigh sensitivity.
\end{abstract}

Keywords: $\mathrm{Ti}_{3} \mathrm{C}_{2}$, nucleus-free $2 \mathrm{D}$ electron gas, monolayer nanosheets, SERS, microwave heating quasi-metals

\section{INTRODUCTION}

Surface-enhanced Raman scattering (SERS) can greatly enhance the weak Raman signal of molecules, which makes it an extremely sensitive nondestructive analytical technique at trace levels $[1,2]$. As a label-free method, SERS has been widely used in various research fields, such as biological and drug sensing $[3,4]$, environmental detection $[5,6]$, molecular fingerprint discriminating $[7,8]$, and catalytic mechanism exploration $[9,10]$. Since Fleischmann and Van Duyne et al. [11-13] discovered SERS on rough silver surface, the search for perfect materials as substrates for SERS is one of the challenges facing material and chemical scientists. An excellent SERS substrate should have the advantages of low cost, high chemical stability, good biocompatibility, and more importantly a vigorous resonance with analytes [14]. In addition, it should be environment-friendly, have abundant reserve, and can be easily processed into desired shape. Various inorganic materials have been developed as substrates for Raman enhancement. The traditional SERS materials are based on noble-metal nanostructures with strong surface plasmon resonance (SPR), in which the electromagnetic mechanism (EM) is regarded as the dominant contribution to the Raman enhancement [1517]. Although the EM-based noble-metal substrates show superior enhancement factors (EFs) of $10^{6}$ or higher, they inevitably suffer from poor biocompatibility, nearly immobilized band structure, excessive cost and so on. In addition to noble-metals, SERS has also been found in semiconductors [18-22], metal-organic frameworks (MOFs) [23] and amorphous materials [24,25], in which Raman enhancement is thought to be the chemical mechanism (CM) caused by the charge-transfer between the analytes and the substrates. Particularly interesting is the recent discovery of SERS activity in conductive polymer films [26]. These results enrich the types of SERS sub-

\footnotetext{
${ }^{1}$ Institute of Industrial and Consumer Product Safety, Chinese Academy of Inspection and Quarantine, Beijing 100176, China

${ }^{2}$ School of Physics and Physical Engineering, Qufu Normal University, Qufu 273165, China

${ }^{3}$ College of Science, Chinese Jiliang University, Hangzhou 310018, China

${ }^{\dagger}$ These two authors contributed equally to this work.

* Corresponding author (email: xiguangcheng@caiq.org.cn)
} 
strates and provide valuable directions for finding efficient substrates. Although these CM-based SERS substrates have the advantage of adjustable band-gap, excellent biocompatibility and low cost, they are generally trapped by the low EFs and poor stability compared with noble-metals, which greatly limits their practical applications. Therefore, the discovery of highly sensitive SERS materials with high stability, low cost and environmental friendliness is a major issue to be solved urgently both in academic and practical perspectives.

As a rising star of photoelectric materials, two-dimensional (2D) ultrathin materials have attracted more and more interests [27-30]. Among them, graphene [31], $\mathrm{MoS}_{2}$ [32], $\mathrm{Ti}_{2} \mathrm{~N}$ [33], and $\mathrm{Mo}(\mathrm{W}) \mathrm{Te}_{2}$ [34] have also joined the SERS substrate family. Because of their uniformity at atomic scale, strong chemisorption, high chemical stability and excellent biocompatibility, these 2D ultrathin nanosheets have been suggested to be promising Raman-enhanced substrates. However, due to the limitation of CM enhancement mechanism, the EFs of 2D SERS substrates are still far less than that of noble-metals. As a most representative member of the $2 \mathrm{D}$ metal carbides (MXenes), $\mathrm{Ti}_{3} \mathrm{C}_{2}$ nanosheets have recently attracted more and more attention due to their high conductivity and high stability as well as very low production costs, showing great potential as high-performance electrode materials, supercapacitors, electrocatalysts, photothermal agents and so on [35-42]. Recently, Sarycheva et al. [43] reported that $\mathrm{Ti}_{3} \mathrm{C}_{2} \mathrm{~T}_{\mathrm{x}}\left(\mathrm{T}_{\mathrm{x}}=-\mathrm{OH},-\mathrm{COOH},-\mathrm{F}\right)$ monolayers also showed SERS activity and $10^{5}-10^{6} \mathrm{EF}$. Although this EF is relatively high, there is still a big gap of $10^{3}$ times compared with the recently reported $\mathrm{W}(\mathrm{Mo}) \mathrm{Te}_{2}$ monolayer nanosheets [34]. Therefore, it is very meaningful to deeply explore the SERS enhancement mechanism of $\mathrm{Ti}_{3} \mathrm{C}_{2}$ monolayers and improve their sensitivity. Eliminating the surface organic groups and obtaining highly crystalline monolayers with clean substrate/molecular interfaces is an effective way to increase the sensing activity [44]. However, the traditional synthesis method (HF method) often introduces a large number of hydroxyl, carbonyl and other organic functional groups on the surface of $\mathrm{Ti}_{3} \mathrm{C}_{2}$ monolayers [37,4042]. How to remove these organic groups without changing the shape and size is a difficult issue, because the common heating method would easily lead to the destruction of its ultrathin structure [45].

Recent studies have shown that, due to the generation of eddy currents, metallic graphene itself will be heated at a very fast rate $(2000 \mathrm{~K} / 0.1 \mathrm{~s})$ under microwave irradiation, thereby greatly improving its crystallinity and even decomposing the metal salts adsorbed on its surface $[46,47]$. Inspired by these work, since $\mathrm{Ti}_{3} \mathrm{C}_{2}$ also has good electrical conductivity $[48,49]$, can it also achieve an increase in crystallinity and elimination of organic groups through the extremely fast microwave heating? Herein, we developed an efficient chemical exfoliation and rapid microwave heating method for the large-scale synthesis of highly crystalline monolayer $\mathrm{Ti}_{3} \mathrm{C}_{2}$ nanosheets. Due to the extremely short microwave irradiation time $(2 \mathrm{~s})$, the morphology and dimensions of the titanium carbide monolayer were not damaged. Benefiting from its unique structure of nucleus-free 2D electron gas (2DEG), these ultrathin $\mathrm{Ti}_{3} \mathrm{C}_{2}$ nanosheets have been found to have outstanding SERS properties. The highly crystalline $\mathrm{Ti}_{3} \mathrm{C}_{2}$ monolayer nanosheets achieve a Raman enhanced factor of $3.82 \times 10^{8}$ and a $10^{-11}$ level limit of detection (LOD) for typical environmental pollutants such as azo dyes, trichlorophenol, and bisphenol A (BPA), which far exceeds most semiconductor substrates and can even be comparable to noble-metal substrates. Single molecule SERS imaging is also realized on the surface of the $\mathrm{Ti}_{3} \mathrm{C}_{2}$ monolayers, which may be the first time that approximate single-molecule imaging has been achieved on a nonnoble-metal SERS substrates.

\section{EXPERIMENTAL SECTION}

\section{Synthesis of highly crystalline monolayer $\mathrm{Ti}_{3} \mathrm{C}_{2}$ nanosheets}

In a typical synthesis, the commercial $\mathrm{Ti}_{3} \mathrm{AlC}_{2}$ was first pulverized into micron-sized particles by a ball mill. After washing and drying, $0.1 \mathrm{~g}$ of the $\mathrm{Ti}_{3} \mathrm{AlC}_{2}$ particles were put into a mixed solution of perchloric acid $\left(\mathrm{HClO}_{4}\right.$, $2 \mathrm{~mol} \mathrm{~L}^{-1}$ ), hydrofluoric acid ( $\mathrm{HF}, 5 \mathrm{~mol} \mathrm{~L}^{-1}$ ) in $100 \mathrm{~mL}$ of distilled water, and stirred gently in a water bath for $12 \mathrm{~h}$ at $50^{\circ} \mathrm{C}$. Note: $\mathrm{HF}$ and $\mathrm{HClO}_{4}$ are corrosive and should be used with extra care. The acid-etched product was separated by centrifugation $(1000 \mathrm{rpm})$. After being washed with deionized water, $0.1 \mathrm{~g}$ of the acid-etched product was poured into $1 \mathrm{~mol} \mathrm{~L}^{-1}$ aqueous solution of ethylenediamine (EN), heated to $60^{\circ} \mathrm{C}$ in a water bath, and gently stirred for $24 \mathrm{~h}$. Then, $0.1 \mathrm{~g}$ of the particles expanded by the EN intercalations were dispersed in $30 \mathrm{~mL}$ of deionized water, and ultrasonically shaken for $2 \mathrm{~h}$. The product was collected by centrifugation $(5000$ $\mathrm{rpm}) .0 .1 \mathrm{~g}$ of the product was dispersed in $100 \mathrm{~mL}$ distilled water for washing three times. After freeze-drying, $0.1 \mathrm{~g}$ of the powders were irradiated in a microwave oven with the power of $700 \mathrm{~W}$ for $2 \mathrm{~s}$. Finally, the product was washed three times with deionized water and absolute ethanol, and dried at $50^{\circ} \mathrm{C}$ for $4 \mathrm{~h}$ in a vacuum oven. 


\section{Constructing flexible $\mathrm{Ti}_{3} \mathrm{C}_{2}$ nanosheet SERS substrate}

In a typical preparation process, $0.3 \mathrm{~g}$ of $\mathrm{Ti}_{3} \mathrm{C}_{2}$ nanosheets were mixed with $50 \mathrm{~mL}$ of ethanol to form a suspension. The suspension was filtered to form a thin layer on the filter paper. After natural drying in air at room temperature, the thin layer of $\mathrm{Ti}_{3} \mathrm{C}_{2}$ was spontaneously separated from the filter paper to form a flexible SERS substrate.

\section{Characterizations}

The obtained samples were systematically characterized by a variety of detection techniques. Powder X-ray diffraction (XRD) patterns of the products were measured on a Bruker D-8 focus X-ray diffractometer by using CuKa radiation $(\lambda=1.54178 \AA)$. Transmission electron microscopy (TEM) and high-resolution TEM (HRTEM) observations were completed with a Tecnai G F30 operated at $300 \mathrm{kV}$ accelerating voltage. Scanning electron microscopy (SEM) images and energy-disperse X-ray spectroscopy (EDS) were obtained on a Hitachi S-4800 with an accelerating voltage of $15 \mathrm{kV}$. The X-ray photoelectron spectroscopy (XPS) measurments were performed in a Theta probe (ESCALab-250Xi Thermo Fisher) by using monochromated $\mathrm{Al} \mathrm{Ka} \mathrm{X}$-rays at $h v=$ $1486.6 \mathrm{eV}$. Peak positions were internally referenced to the $\mathrm{C} 1 \mathrm{~s}$ peak at $284.6 \mathrm{eV}$. UV-Vis absorption spectra were detected with a Shimadzu UV-3600. The Fourier transform infrared (FTIR) spectra were measured from a THERMO Iz-10. The specific surface area was detected in a Micro Tristar II 3020. Atomic force microscopy (AFM) image was recorded from Agilent Technologies 5500.

\section{Raman property test}

A laser-confocal-micro-Raman spectrometer (RenishawinVia Reflex) was used as the measuring equipment to detect the SERS properties of the as-prepared $\mathrm{Ti}_{3} \mathrm{C}_{2}$ nanosheets. In all the experiments mentioned in this work, if there is no definite indication, the used excitation wavelengths were all $532 \mathrm{~nm}$, the magnification of the objective was $\times 100 \mathrm{~L}$, and the excitation power was $0.5 \mathrm{~mW}$. A series of standard solutions (R6G) with concentrations of $10^{-2}-10^{-11} \mathrm{~mol} \mathrm{~L}^{-1}$ were used as the probe molecules. To improve the signal reproducibility and uniformity of the SERS substrates, the $\mathrm{Ti}_{3} \mathrm{C}_{2}$ nanosheet flexible substrates were added into a probe molecule aqueous solution to be measured and maintained for $20 \mathrm{~min}$. After $3 \mathrm{~min}$, the obtained flexible substrate was coated on a glass slide, and then dried in air for $5 \mathrm{~min}$ under the irradiation of a infrared light $(200 \mathrm{~W})$. In all SERS detections, the laser beam was perpendicular to the top of the sample to be tested with a resultant beam spot diameter of $5 \mu \mathrm{m}$. Raman enhanced factor calculation details are provided in the Supplementary information.

\section{Cytotoxicity of the monolayer $\mathrm{Ti}_{3} \mathrm{C}_{2}$ nanosheets}

Human cervix carcinoma cell lines (Hela) used in this study were purchased from the National Infrastructure of Cell Line Resource (Beijing, China). Cells were cultured in RPMI1640 medium and supplemented with $10 \%$ fetal bovine serum (Gibco), $2 \mathrm{mmol} \mathrm{L}^{-1} \quad L$-glutamine, $100 \mathrm{U} \mathrm{mL}^{-1}$ penicillin and $1 \mathrm{mg} \mathrm{mL}^{-1}$ streptomycin (Invitrogen) at $37^{\circ} \mathrm{C}$ in an incubator with $95 \%$ air and $5 \%$ $\mathrm{CO}_{2}$. For cytotoxicity, cells were seeded in two parallel 96well cell culture plates at 5000 cells per well and incubated for $12 \mathrm{~h}$. Then the cells were treated with a series of concentrations of $\mathrm{Ti}_{3} \mathrm{C}_{2}$ nanosheets $(0,7.5,15,31,62,125$, 250, 500 and $1000 \mu \mathrm{g} \mathrm{m}^{-1}$ ) for 24 and $48 \mathrm{~h}$ respectively. The relative cellular viabilities were quantitatively determined by the Alamar Blue ${ }^{\circledR}$ (Thermo Fisher Technology Inc.) assay. For cellular apoptosis detection, cells were seeded in two parallel 6-well cell culture plates at $5 \times 10^{4}$ cells per well and incubated for $12 \mathrm{~h}$. Then three wells of cells were exposed to $\mathrm{Ti}_{3} \mathrm{C}_{2}$ nanosheets at the concentration of $1000 \mu \mathrm{g} \mathrm{mL}^{-1}$ for $48 \mathrm{~h}$. After exposure, one plate of cells were incubated in $55^{\circ} \mathrm{C}$ water bath for $10 \mathrm{~min}$ as the positive control of late apoptosis. All cells were co-stained with $1 \mathrm{mg} \mathrm{mL}^{-1}$ acridine orange and ethidium bromide (AO/EB). The cell apoptosis was detected with a micro-confocal and high content screening system (HCA, Image Xpress micro XLS, Molecular Devices Corporation, USA).

\section{Electronic structure calculation}

All density functional theory (DFT) calculations were performed by using Vienna ab initio Simulation Package (VASP). The calculation details are provided in the Supplementary information.

\section{RESULTS AND DISCUSSION}

\section{Synthesis and characterization of the highly crystalline $\mathrm{Ti}_{3} \mathrm{C}_{2}$ monolayers}

Compared with the products prepared by the physical vapor deposition (PVD), the ultrathin nanosheets prepared by chemical exfoliation often inevitably have poor crystallinity due to strong acid corrosion and ultrasonic damage. In order to obtain high crystallinity, these monolayer $\mathrm{Ti}_{3} \mathrm{C}_{2}$ nanosheets were prepared by an improved chemical exfoliation method. Compared with the previous methods, this method greatly enhanced the 
crystallinity of the obtained $\mathrm{Ti}_{3} \mathrm{C}_{2}$ monolayer, which is very beneficial to the formation of strong SPR effect and interface charge-transfer effect. In a typical synthesis, as shown in Fig. 1, firstly, commercial $\mathrm{Ti}_{3} \mathrm{AlC}_{2}$ powders were ground into micron-sized particles (Fig. 2a) by ball milling; then, these $\mathrm{Ti}_{3} \mathrm{AlC}_{2}$ microparticles were corroded in a mixture of $\mathrm{HClO}_{4}$ and $\mathrm{HF}$ to remove the $\mathrm{Al}$ layer (Fig. 2b); and the Al-removed microparticles were injected into the EN solution for molecular-intercalation. The expanded samples were then dispersed into a monolayer of $\mathrm{Ti}_{3} \mathrm{C}_{2}$ by ultrasonic vibration; finally, the crystallinity of these $\mathrm{Ti}_{3} \mathrm{C}_{2}$ nanosheets was rapidly improved by microwave heating. In particular, it should be pointed out that the addition of a small amount of $\mathrm{HClO}_{4}$ is a key to obtain the high-quality monolayer $\mathrm{Ti}_{3} \mathrm{C}_{2}$ nanosheets, because without $\mathrm{HClO}_{4}$, it is difficult to completely remove the $\mathrm{Al}$ component. However, the concentration of $\mathrm{HClO}_{4}$ should not exceed $3.5 \mathrm{~mol} \mathrm{~L}^{-1}$, otherwise the $\mathrm{Ti}_{3} \mathrm{C}_{2}$ layer will be corroded due to the strong oxidation of $\mathrm{HClO}_{4}$ [49]. In addition, microwave heating is also a key step to obtain the highly crystallized $\mathrm{Ti}_{3} \mathrm{C}_{2}$ nanosheets. Without this rapid heating process, the crystallinity of the obtained nanosheets is poor, and the EF of the nanosheets would be reduced by two orders of magnitude.

By the method described above, we have obtained a well dispersed sample of monolayer $\mathrm{Ti}_{3} \mathrm{C}_{2}$ nanosheets, which can be stored in water and ethanol stably (Fig. S1). XRD patterns show that these samples can be accurately indexed as $\mathrm{Ti}_{3} \mathrm{C}_{2}$ monolayers, and no diffraction peaks of
$\mathrm{Ti}_{3} \mathrm{AlC}_{2}$ are detected (Fig. S2). The SEM image shows that the prepared $\mathrm{Ti}_{3} \mathrm{C}_{2}$ samples are indeed composed of a large number of flexible nanosheets (Fig. 2c). It is noteworthy that the thickness of these nanosheets is very thin, and the electron beam can easily penetrate these nanosheets. TEM further demonstrates that these samples contain soft and ultrathin $\mathrm{Ti}_{3} \mathrm{C}_{2}$ nanosheets (Fig. 2d). The EDS obtained on the copper microgrid shows that the atomic ratio of $\mathrm{Ti}$ to $\mathrm{C}$ in the sample is about 1.53 , which is basically consistent with the theoretical value of titanium carbide (Fig. S3). In order to accurately characterize the thickness of these nanosheets, AFM was used to measure these nanosheets. The results show that the thickness of these nanosheets is about $1.22 \mathrm{~nm}$ (Fig. 2e). Compared with the theoretical calculation of the thickness of $\mathrm{Ti}_{3} \mathrm{C}_{2}$ monolayer $(0.98 \mathrm{~nm})$ [40], the thickness of the nanosheet obtained in our experiment increases by 0.24 nanometer, which may be caused by the adsorbed water molecules and carbon dioxide molecules on the surface of the nanosheet [41]. Furthermore, HRTEM image reveals that these monolayer $\mathrm{Ti}_{3} \mathrm{C}_{2}$ nanosheets have clear lattice fringes (Fig. 2f). The corresponding fast Fourier transform (FFT) pattern also proves this high crystallinity (inset in Fig. 2f). All the above results indicate that highly crystallized monolayer $\mathrm{Ti}_{3} \mathrm{C}_{2}$ nanosheets have been successfully prepared by the present method.

XPS was performed to further explore the composition and surface chemistry of the monolayer $\mathrm{Ti}_{3} \mathrm{C}_{2}$ nanosheets.

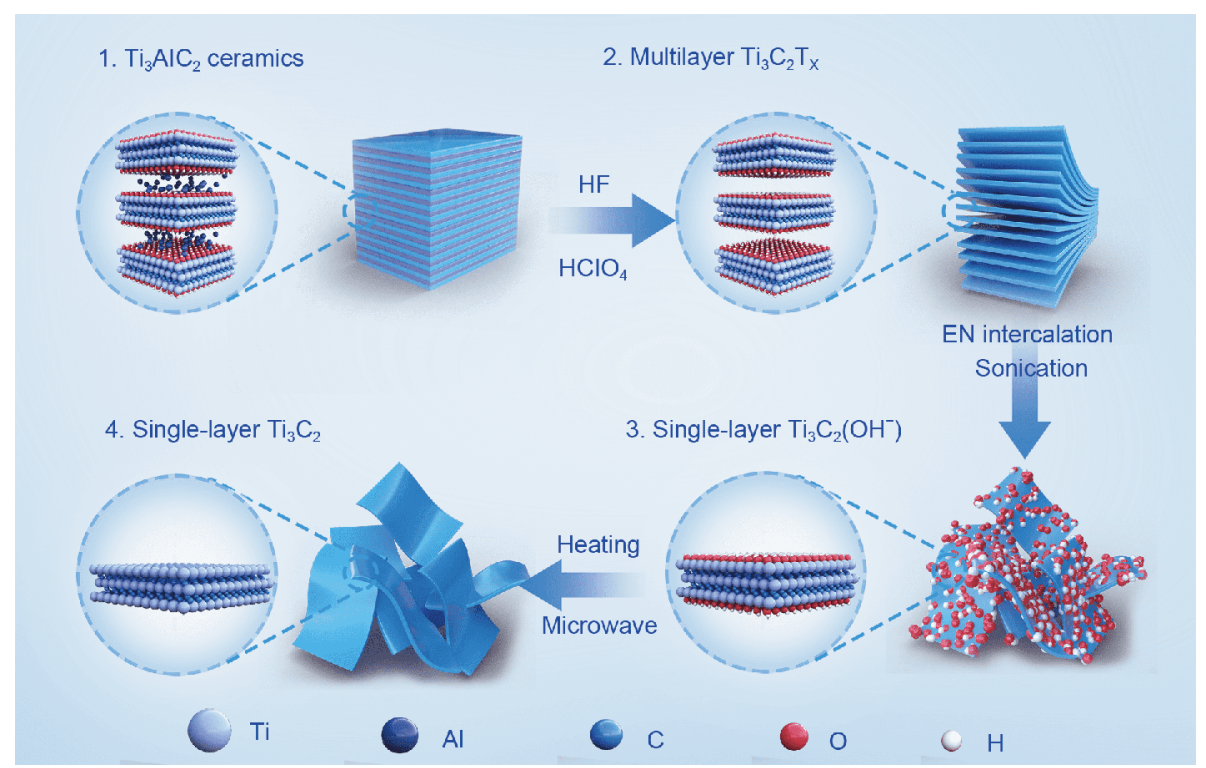

Figure 1 Schematic diagram for the synthesis of highly crystalline monolayer $\mathrm{Ti}_{3} \mathrm{C}_{2}$ nanosheets. Note: $\mathrm{HF}$ and $\mathrm{HClO}_{4}$ are corrosive and should be used with extra care. 


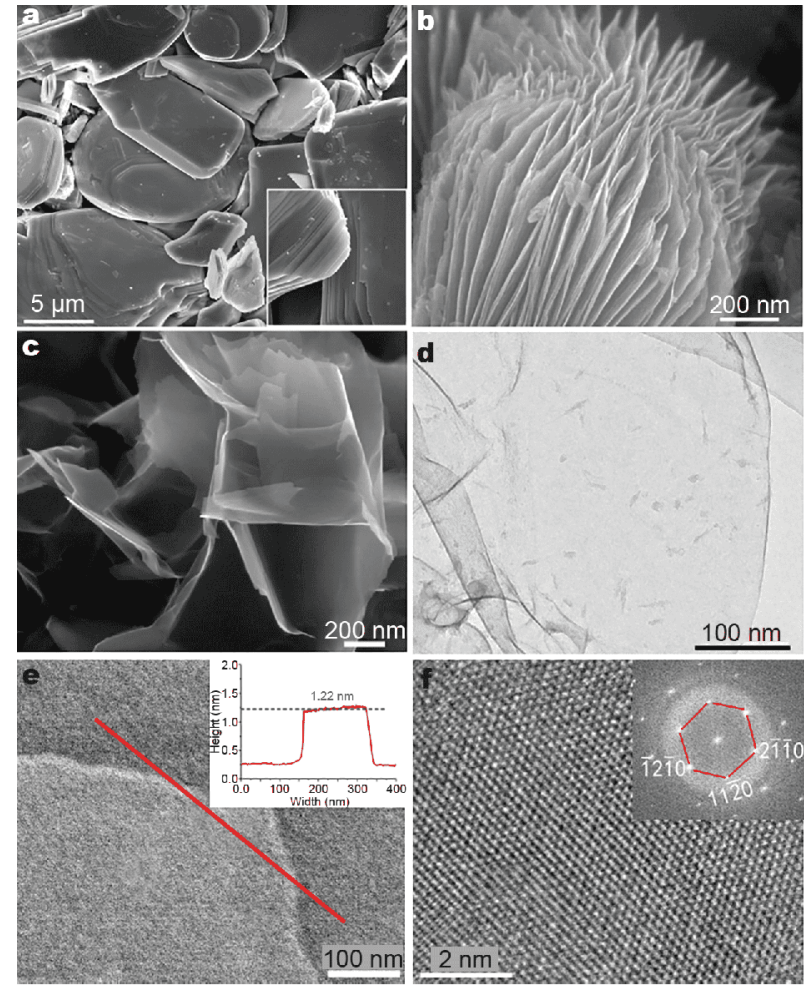

Figure 2 Morphology and structure characterizations of the $\mathrm{Ti}_{3} \mathrm{AlC}_{2}$ precursor and the monolayer $\mathrm{Ti}_{3} \mathrm{C}_{2}$ nanosheets. (a) The commercial $\mathrm{Ti}_{3} \mathrm{AlC}_{2}$ powders after grinding. (b) The multilayer $\mathrm{Ti}_{3} \mathrm{C}_{2}$ nanosheets obtained by $\mathrm{HClO}_{4}$ and $\mathrm{HF}$ etching. (c) The SEM image of the monolayer $\mathrm{Ti}_{3} \mathrm{C}_{2}$ nanosheets. (d) TEM image of the monolayer $\mathrm{Ti}_{3} \mathrm{C}_{2}$ nanosheets. (e) AFM image of the $\mathrm{Ti}_{3} \mathrm{C}_{2}$ nanosheets. (f) HRTEM image of the monolayer $\mathrm{Ti}_{3} \mathrm{C}_{2}$ nanosheets, inset: FFT pattern of the nanosheet.

The data were calibrated based on the peak of $\mathrm{C}-\mathrm{C}$ bond located at $284.8 \mathrm{eV}$. A survey spectrum of $\mathrm{Ti}_{3} \mathrm{C}_{2}$ nanosheets indicated the presence of $\mathrm{Ti}, \mathrm{C}$, and $\mathrm{O}$ atoms (Fig. S4). The high-resolution XPS spectrum for Ti $2 p$ is shown in Fig. 3a. The peaks located at 453.8 and $461.7 \mathrm{eV}$ prove the presence of $\mathrm{Ti}-\mathrm{C}$ bonding in the $\mathrm{Ti}_{3} \mathrm{C}_{2}$ nanosheets, whereas the low peak at $457.1 \mathrm{eV}$ can be attributed to the $\mathrm{Ti}-\mathrm{O}$ bond. It is worth pointing out that such well-defined XPS spectrum is rarely seen in $\mathrm{Ti}_{3} \mathrm{C}_{2}$ nanosheets prepared by traditional chemical exfoliation. In sharp contrast, the $\mathrm{Ti}_{3} \mathrm{C}_{2}$ monolayers that have not been subjected to microwave heating show multiple Ti-O bonds at 455.20, 456.52, 458.42, 460.31 and $461.42 \mathrm{eV}$ (Fig. 3b). Obviously, they originate from the Ti-O bonds with different oxidation states of $\mathrm{Ti}$, and their strength is significantly increased compared with that of $\mathrm{Ti}-\mathrm{C}$ bonds, which is highly consistent with the results of $\mathrm{Ti}_{3} \mathrm{C}_{2} \mathrm{~T}_{\mathrm{x}}$ monolayer nanosheets reported earlier [37,41]. The two distinct XPS spectra prove that microwave heating is an effective method for removing groups introduced by synthetic processes such as hydroxyl groups on the surface of $\mathrm{Ti}_{3} \mathrm{C}_{2}$ monolayers.

It should be pointed out that the addition of $\mathrm{EN}$ is also a key factor in the formation of the monolayer $\mathrm{Ti}_{3} \mathrm{C}_{2}$ nanosheets. EN has been used as chelating agent in nanosynthesis for a long time due to its strong coordination ability to guide the formation of special nanostructures [50]. Herein, two $\mathrm{N}$ atoms of EN molecule can form Ti-N coordination bond with $\mathrm{Ti}_{3} \mathrm{C}_{2}$, which can be easily inserted into the layered structure of $\mathrm{Ti}_{3} \mathrm{C}_{2}$ to play the role of expansion molecule. After intensive ultrasound treatment, a large number of monolayer $\mathrm{Ti}_{3} \mathrm{C}_{2}$ nanosheets were formed. In contrast, without EN added, the final sample was a multilayer $\mathrm{Ti}_{3} \mathrm{C}_{2}$ nanosheets consisting of 36 layers (Fig. 3c and Fig. S5). At the same time, we should emphasize the importance of microwave heating. In general, the crystallinity of the $\mathrm{Ti}_{3} \mathrm{C}_{2}$ nanosheets will inevitably decrease significantly after strong acid corrosion and intense ultrasound treatment, which is unfavorable for their applications in many aspects, especially in photoelectric applications. Fig. 3d shows an HRTEM image of the monolayer $\mathrm{Ti}_{3} \mathrm{C}_{2}$ nanosheets without microwave heating. It is obvious that many lattice defects exist in the nanosheets, apparently due to corrosion and ultrasound. This difference in crystallinity has a significant effect on their properties. For example, highly crystallized $\mathrm{Ti}_{3} \mathrm{C}_{2}$ samples show strong localized-SPR effect in the visible region (Fig. S6), while the absorption spectrum of $\mathrm{Ti}_{3} \mathrm{C}_{2} \mathrm{~T}_{\mathrm{x}}$ monolayer nanosheets with a large number of defects has a significant red shift, showing an obvious lattice defect absorption. Generally, the excitation wavelengths commonly used in SERS experiments are 532 and $633 \mathrm{~nm}$, respectively. It is obvious that high crystallinity $\mathrm{Ti}_{3} \mathrm{C}_{2}$ nanosheets can more easily resonate with the incident excited light, which is a necessary condition for the formation of strong Raman enhancement.

\section{Enhanced Raman scattering properties of the $\mathrm{Ti}_{3} \mathrm{C}_{2}$ monolayers}

Next, we systematically investigated the SERS properties of these monolayer $\mathrm{Ti}_{3} \mathrm{C}_{2}$ nanosheets. Unlike those SERS substrates based on nanoparticles prepared by spincoating method, these ultrathin $\mathrm{Ti}_{3} \mathrm{C}_{2}$ nanosheets can easily form large-area flexible substrates by simple filtration (Fig. 4a), without glass, silicon and other substrates, which greatly simplifies the substrate preparation process. The detection process is also very simple. After dipping these flexible substrates in the solution to be tested, and then quickly drying under the infrared lamp, they can be placed on the loading table for testing. Without special 

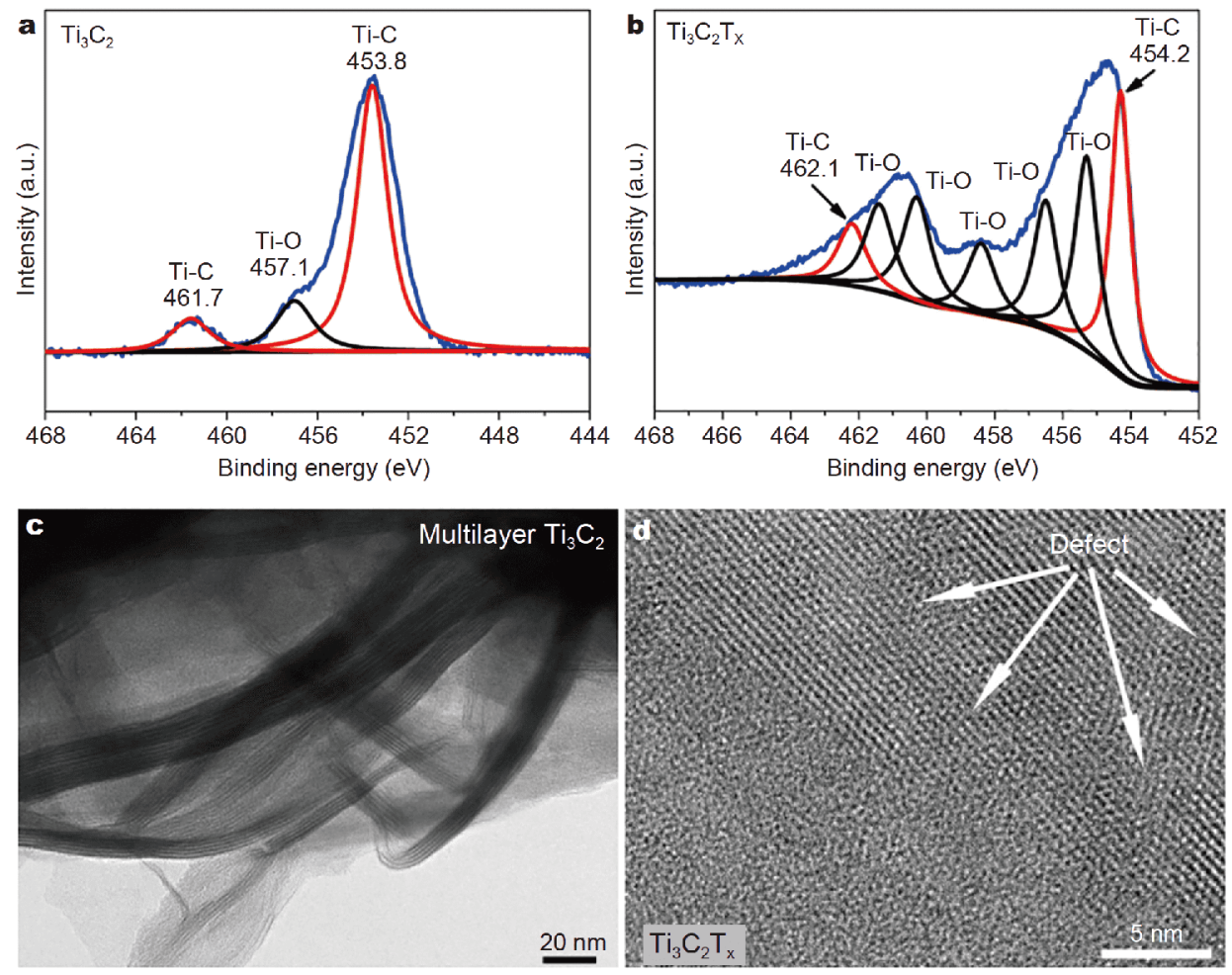

Figure 3 (a) XPS spectrum of the monolayer $\mathrm{Ti}_{3} \mathrm{C}_{2}$ nanosheets. (b) XPS spectrum of the monolayer $\mathrm{Ti}_{3} \mathrm{C}_{2} \mathrm{~T}_{\mathrm{x}}$ nanosheets without microwave heating. (c) HRTEM image of the as-synthesized multilayer $\mathrm{Ti}_{3} \mathrm{C}_{2}$ nanosheets. (d) HRTEM image of the obtained monolayer $\mathrm{Ti}_{3} \mathrm{C}_{2}$ nanosheets without microwave heating.

explanation, in all Raman detections, the objective lens used in the experiment was $100 \times$, the excitation power was $0.5 \mathrm{~mW}$, and the excitation wavelength was $532 \mathrm{~nm}$. The results show that the monolayer $\mathrm{Ti}_{3} \mathrm{C}_{2}$ nanosheets have a strong SERS effect on the probe molecule R6G (Fig. 4b). It is clear that four typical Raman scattering peaks of R6G, $R_{1}, R_{2}, R_{3}, R_{4}$, are highly consistent with the Raman spectra of R6G reference materials (Fig. S7). Through the detection of a series of R6G samples with different concentrations, we can see that in a large concentration range, the $\mathrm{Ti}_{3} \mathrm{C}_{2}$ nanosheets have a good response to the probe molecules, and the lowest detection limit can even reach $10^{-11} \mathrm{~mol} \mathrm{~L}^{-1}$. The Raman EF of the $\mathrm{Ti}_{3} \mathrm{C}_{2}$ nanosheets was obtained by calculating the signal enhancement multiples of the two scattering peaks $R_{1}$ and $\mathrm{R}_{2}$ of $\mathrm{R} 6 \mathrm{G}$ at three concentrations over the $\mathrm{Ti}_{3} \mathrm{C}_{2}$ nanosheets. As shown in Fig. 4c, compared with the signal intensities obtained over the glass, the calculation results show that the maximum EF of the $\mathrm{Ti}_{3} \mathrm{C}_{2}$ nanosheets is $3.82 \times 10^{8}$ at $10^{-10} \mathrm{~mol} \mathrm{~L}^{-1}$, which is comparable to the record of noble-metal substrates, but with much lower cost. These experimental results demonstrate that the monolayer $\mathrm{Ti}_{3} \mathrm{C}_{2}$ nanosheets have a very high Raman signal enhancement ability and a very high sensitivity to the analyte.

In addition to sensitivity, the uniformity and reproducibility of signals on the substrates are another important evaluation factor from a practical point of view. For this reason, we randomly detected 20 points in the range of $1 \mathrm{~cm}^{2}$ on this flexible substrate. The results show that the peak intensities of the 20 Raman spectra of R6G are highly consistent (Fig. 4d). In order to evaluate the signal uniformity of this substrate more accurately, we used Raman mapping technology to scan 10,000 ordered points in $160 \mathrm{~mm}^{2}$. Statistical analysis of their $R_{1}$ peak intensities reveals that their relative standard deviation is only $5.2 \%$ (Fig. 4 e), which can be attributed to the uniformity of their atomic level. The corresponding Raman mapping image also demonstrates this high signal uniformity (Fig. 4f). It is precisely because of the high homogeneity of the substrate that a good linear relationship exists between the analyte concentration and the signal intensity (Fig. S8). These excellent properties are very important for actual analysis. As mentioned above, the LOD of these $\mathrm{Ti}_{3} \mathrm{C}_{2}$ monolayers to $\mathrm{R} 6 \mathrm{G}$ is up to $10^{-11} \mathrm{~mol} \mathrm{~L}^{-1}$, which approaches or reaches single-mole- 

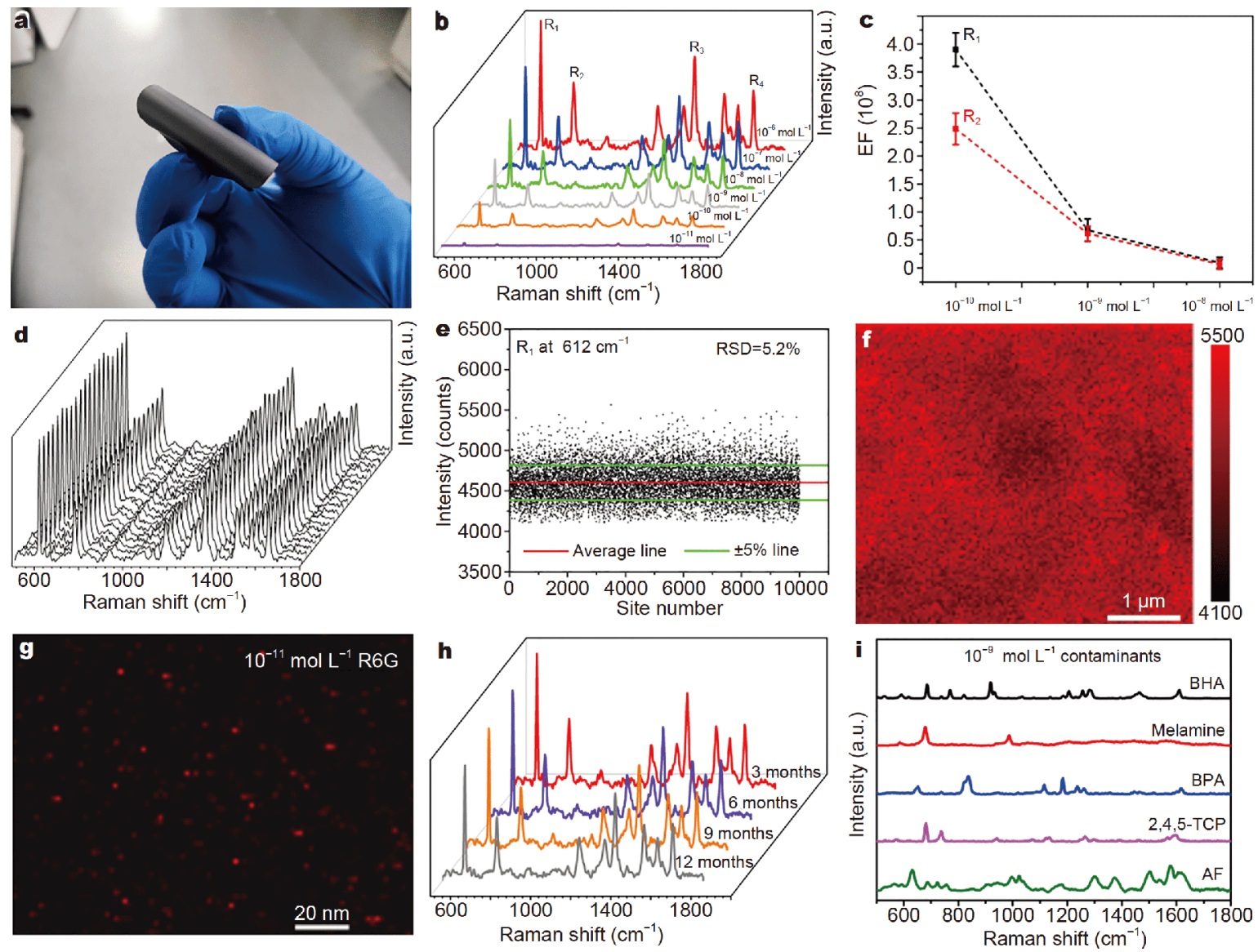

Figure 4 SERS properties of the flexible $\mathrm{Ti}_{3} \mathrm{C}_{2}$ nanosheets. (a) Flexible SERS substrate based on the $\mathrm{Ti}_{3} \mathrm{C}_{2}$ ultrathin nanosheets. (b) Raman spectra of $10^{-6}-10^{-11} \mathrm{~mol} \mathrm{~L}^{-1}$ R6G obtained in the flexible SERS substrate. (c) The average Raman EFs obtained by counting the peak intensities $\left(\mathrm{R}_{1}\right.$ and $\left.\mathrm{R}_{2}\right)$ at three different concentration levels. (d) SERS signals collected from 20 randomly selected points on the substrate. (e) The signal intensity distribution at $612 \mathrm{~cm}^{-1}$ of $10^{-8} \mathrm{~mol} \mathrm{~L}^{-1}$ R6G recorded from 10,000 sites. (f) The signal intensity distribution recorded by SERS mapping at $612 \mathrm{~cm}^{-1}$ of $10^{-8} \mathrm{~mol} \mathrm{~L}^{-1}$ R6G in the substrate. (g) Single-molecule SERS spots recorded from $10^{-11} \mathrm{~mol} \mathrm{~L}^{-1}$ R6G. (h) SERS spectra of Ti $\mathrm{C}_{3} \mathrm{C}_{2}$ ultrathin nanosheets stored in air for 3-12 months. (i) SERS spectra of a series of harmful substances: butyl hydroxy anisd (BHA), melamine, BPA, 2,4,5-TCP, and acid fuchsin $(\mathrm{AF})$.

cule level [26]. Based on such high sensitivity, it is expected to make single molecule SERS imaging. As shown in Fig. 4g, a clear single-molecule (or near single-molecule) SERS imaging of $10^{-11} \mathrm{~mol} \mathrm{~L}^{-1}$ R6G was successfully achieved on the $\mathrm{Ti}_{3} \mathrm{C}_{2}$ monolayers. To the best of our knowledge, this may be the first time that approximate single-molecule imaging has been achieved on a nonnoble-metal SERS substrate. Moreover, due to the inherent high stability of metal carbides, the chemical stability of these $\mathrm{Ti}_{3} \mathrm{C}_{2}$ nanosheets is considerablely high. Even if stored in air for half a year to one year, they still have a high degree of crystallinity (Fig. S9) and their SERS properties do not decrease significantly (Fig. $4 \mathrm{~h}$ ). In addition, for high-risk chemicals, such as BPA, dichlorophenol (DCP), and tetrachlorophenol (TCP), which are widely concerned, these $\mathrm{Ti}_{3} \mathrm{C}_{2}$ nanosheets also show high sensitivities (Fig. 4i), showing a good universality as a practical SERS substrate.

\section{Raman enhancement mechanism}

In order to understand the enhancement mechanism of this highly sensitive quasi-metallic $\mathrm{Ti}_{3} \mathrm{C}_{2}$ monolayer SERS substrate, we explored it by combining experimental and theoretical calculations. The $\mathrm{Ti}_{3} \mathrm{C}_{2}$ structure unit can be defined as trilayer $\mathrm{Ti}$-atomic layers being interleaved with two $\mathrm{C}$-atomic layers, forming an edge-shared $\mathrm{TiC}_{6}$ octahedral structure (Fig. S10). Interestingly, the results of the DFT calculations reveal that the $\mathrm{Ti}_{3} \mathrm{C}_{2}$ monolayer possesses intrinsic nucleus-free 2DEG in free space, which is similar to the $\mathrm{Ga}_{2} \mathrm{~N}$ monolayer [51], and the 2DEG distributes among the edge Ti atoms (Fig. 5a), indicating the strong chemical activity of $\mathrm{Ti}_{3} \mathrm{C}_{2}$ monolayer. It should be 

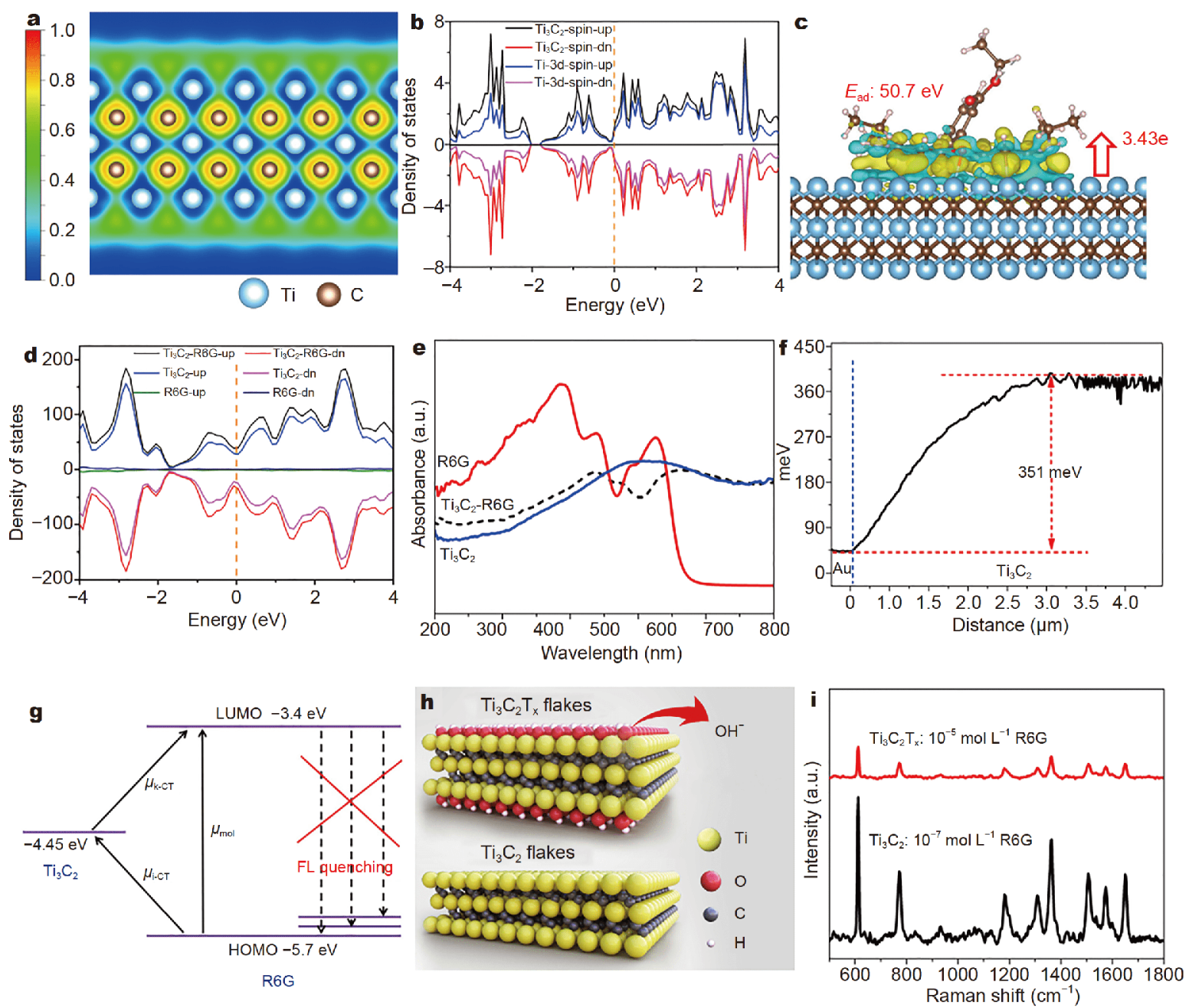

Figure 5 Enhancement mechanism of the monolayer $\mathrm{Ti}_{3} \mathrm{C}_{2}$ nanosheets. (a) The electronic local function (ELF) of $\mathrm{Ti}_{3} \mathrm{C}_{2}$ with a scale bar from zero at the low end to one at the high end. (b) The DOS of $\mathrm{Ti}_{3} \mathrm{C}_{2}$ near the Fermi levels. (c) Side views of the electron density differences for R6G chemisorbed onto the $\mathrm{Ti}_{3} \mathrm{C}_{2}$ surface, in which the isosurface was set to $2 \times 10^{-3} \mathrm{e} \AA^{-3}$, and the Bader charge analysis indicates there are $3.43 \mathrm{e}$ transferring from $\mathrm{Ti}_{3} \mathrm{C}_{2}$ surface to R6G. (d) The DOS of R6G adsorbed on the $\mathrm{Ti}_{3} \mathrm{C}_{2}$ surface. (e) Absorption spectra for R6G on the monolayer Ti ${ }_{3} \mathrm{C}_{2}$ nanosheets compared with pure monolayer $\mathrm{Ti}_{3} \mathrm{C}_{2}$ nanosheets and R6G. (f) The measured surface potential difference profiles. (g) Energy level distribution and PICT in the R6G- $\mathrm{Ti}_{3} \mathrm{C}_{2}$ complex. (h) Structure diagram of the $\mathrm{Ti}_{3} \mathrm{C}_{2}$ nanosheets and $\mathrm{Ti}_{3} \mathrm{C}_{2} \mathrm{~T}_{\mathrm{x}}$ nanosheets. (i) Comparison of the SERS performance of the Ti ${ }_{3} \mathrm{C}_{2}$ nanosheets and $\mathrm{Ti}_{3} \mathrm{C}_{2} \mathrm{~T}_{\mathrm{x}}$ nanosheets.

noted that this unique 2DEG in the surface of the $\mathrm{Ti}_{3} \mathrm{C}_{2}$ monolayer provides an ideal transport channel without nuclear scattering, which would greatly promote the interface charge-transfer and increase the Raman scattering cross-section of the adsorbed molecules. The further electronic structure calculations show the 2DEG is composed of Ti $3 \mathrm{~d}$ orbitals, presenting a strong metallic feature rather than semiconducting characteristic (Fig. 5b). Due to the existence of a high density of free electrons, these $\mathrm{Ti}_{3} \mathrm{C}_{2}$ monlayers exhibit strong SPR in the visible region (Fig. S6). Dravid et al. [40] found that high density magnetic field "hot spots" exist between these ultrathin $\mathrm{Ti}_{3} \mathrm{C}_{2}$ nanosheets, which suggests that $\mathrm{EM}$ enhancement exists in this quasi-metallic 2D SERS substrate.

Importantly, DFT calculations show that the binding energy between $\mathrm{R} 6 \mathrm{G}$ and $\mathrm{Ti}_{3} \mathrm{C}_{2}$ monolayer and the number of electron transport (Fig. $5 \mathrm{c}$ ) were pretty high. The binding energy is up to $5.07 \mathrm{eV}$, which is more than seven times that between $\mathrm{WTe}_{2}$ and $\mathrm{R} 6 \mathrm{G}$ reported recently $(0.67 \mathrm{eV})$, and far exceeds that betwenn graphene and $\mathrm{R} 6 \mathrm{G}(0.24 \mathrm{eV})$ [34]. This indicates that there is a very strong interfacial interaction between $\mathrm{R} 6 \mathrm{G}$ and $\mathrm{Ti}_{3} \mathrm{C}_{2}$ monolayer. At the same time, by using the Bader's 
quantum theory of atoms in molecules (QTAIM) charge analysis [52], there are 3.43 electrons per unit transferred from the $\mathrm{Ti}_{3} \mathrm{C}_{2}$ monolayer to $\mathrm{R} 6 \mathrm{G}$, which is about three times that of the $\mathrm{WTe}_{2}$ and R6G system (1.26 e), and far exceeds that of graphene and R6G (0.46 e) [34]. The high binding energy and the large amount of charge transfer reveal that the coupling of $\mathrm{R} 6 \mathrm{G}-\mathrm{Ti}_{3} \mathrm{C}_{2}$ is much stronger than that of $\mathrm{WTe}_{2}$ and graphene with R6G. More interestingly, the density of states (DOS) near the Fermi level of $\mathrm{Ti}_{3} \mathrm{C}_{2}$ monolayer increases significantly after R6G adsorption (Fig. $5 \mathrm{~d}$ ), the d-band center increases from 0.61 to $0.85 \mathrm{eV}$, which not only demonstrates that the analyte has a strong interfacial-charge-transfer with the substrate, but also indicates that the analyte improves the electron concentration near the fermi level of the substrate, and further gives rise to the high charge transition probabilities according to the Fermi's golden rule.

Furthermore, due to the relatively high surface activity of $\mathrm{Ti}_{3} \mathrm{C}_{2}$ monolayer, shown in the charge density difference isosurfaces, the electrons go through a self-charge transfer process and concentrate at the $\mathrm{R} 6 \mathrm{G} / \mathrm{Ti}_{3} \mathrm{C}_{2}$ interface, forming a quasi-covalent bond, which will enhance the electron coupling between $\mathrm{R} 6 \mathrm{G}$ and the $\mathrm{Ti}_{3} \mathrm{C}_{2}$ monolayer. The electron transfer also forms a strong dipole between the $\mathrm{R} 6 \mathrm{G}$ and $\mathrm{Ti}_{3} \mathrm{C}_{2}$, which will improve the electrostatic attraction of the dipole and further enhance the Raman scattering of $\mathrm{R} 6 \mathrm{G}$ on the $\mathrm{Ti}_{3} \mathrm{C}_{2}$ monolayer. The results of calculations have also been confirmed by experiments. As shown in Fig. 5e, the main absorption bands of R6G adsorbed on the $\mathrm{Ti}_{3} \mathrm{C}_{2}$ monolayer have changed significantly, which undoubtedly proves that the charge-transfer behavior occurs at the $\mathrm{Ti}_{3} \mathrm{C}_{2} / \mathrm{R} 6 \mathrm{G}$ interface. Therefore, the strong dipole interaction and the quasi-covalent bond interaction greatly enhance the interface charge-transfer between the analyte and the substrate, and increase the Raman scattering cross-section of the analyte molecule.

The excellent Raman enhancement behavior of $\mathrm{Ti}_{3} \mathrm{C}_{2}$ nanosheets can also be attributed to the $\mathrm{CM}$ enhancement caused by photoinduced charge transfer (PICT). As shown in Fig. 5f, considering that the work function of $\mathrm{Au}$ reference is $4.8 \mathrm{eV}$, the work function of $\mathrm{Ti}_{3} \mathrm{C}_{2}$ monolayers is estimated to be $4.8-0.351=4.45 \mathrm{eV}$ according to the work function measurement by Kelvin probe force microscope (KPFM). The $\mathrm{Ti}_{3} \mathrm{C}_{2}$ thickness dependence of its work function can be neglected. The energy level distribution and the possible PICT process in the R6G-Ti ${ }_{3} \mathrm{C}_{2}$ complex are shown in Fig. $5 \mathrm{~g} . \mu_{\mathrm{mol}}$ denotes the molecular transition. $\mu_{\mathrm{i}-\mathrm{CT}}$ and $\mu_{\mathrm{k} \text {-СT }}$ denote the charge transfer transitions from the molecular ground states to
$\mathrm{Ti}_{3} \mathrm{C}_{2}$ and from $\mathrm{Ti}_{3} \mathrm{C}_{2}$ to the molecular excited states, respectively. According to early research reports, the energy levels of the highest occupied molecular orbital (HOMO) and lowest occupied molecular orbital (LUMO) of R6G are -5.7 and $-3.4 \mathrm{eV}$, respectively. This energy level distribution makes PICT possible. In this process, the excited electrons can be transferred not only from the HOMO of R6G to the Fermi level of $\mathrm{Ti}_{3} \mathrm{C}_{2}$ monolayers, but also from the Fermi level of $\mathrm{Ti}_{3} \mathrm{C}_{2}$ monolayers to the LUMO of R6G. Therefore, according to the well-known Herzberg-Teller vibration coupling law, the molecule resonance caused by the interface PICT greatly enhances the polarization tensor of the $\mathrm{R} 6 \mathrm{G}$ molecule. It is particularly noteworthy that the Fermi level of $\mathrm{Ti}_{3} \mathrm{C}_{2}$ monolayers is almost symmetrically matched to the HOMO and LUMO of R6G (Fig. 5g), which greatly reduces the interference of the luminescence background of the R6G molecule itself.

In addition, our study found that high crystalline and clean surface of the monolayer nanosheets can greatly promote their SERS performances. It is mentioned above that without the final microwave heating, the prepared $\mathrm{Ti}_{3} \mathrm{C}_{2} \mathrm{~T}_{\mathrm{x}}(\mathrm{T}=\mathrm{OH})$ nanosheets have low crystallinity and a large number of $-\mathrm{OH}$ radicals on their surfaces. It should be noted that a large number of crystal defects and surface active groups can often promote the catalytic activity of titanium carbide; however, the experimental results show that the SERS effect of the $\mathrm{Ti}_{3} \mathrm{C}_{2} \mathrm{~T}_{\mathrm{x}}$ nanosheets as the substrate is much lower than that of the $\mathrm{Ti}_{3} \mathrm{C}_{2}$ nanosheets after microwave heating (Fig. $5 \mathrm{~h}, \mathrm{i}$ ). This is because a large number of hydroxyl radicals on the surface of $\mathrm{Ti}_{3} \mathrm{C}_{2} \mathrm{~T}_{\mathrm{x}}$ hinder the charge transfer between the adsorbed molecule and the substrate, while a large number of crystal defects further restrict the charge transfer and SPR. Therefore, microwave heating is a simple and effective way to enhance the SERS performance of these ultrathin nanosheets by improving the crystallinity and eliminating the hydroxyl groups on the surface.

\section{Toxicity of the monolayer $\mathrm{Ti}_{3} \mathrm{C}_{2}$ nanosheets}

The safety and biocompatibility of the active SERS material are essential for its application in the biosensor and detection fields. We evaluated the in vitro toxicity of $\mathrm{Ti}_{3}$ $\mathrm{C}_{2}$ monolayers briefly using Hela cell lines. In order to obtain a more reliable toxicity conclusion, we set the concentration of $\mathrm{Ti}_{3} \mathrm{C}_{2}$ monolayers used in the toxicity experiment to $1000 \mu \mathrm{g} \mathrm{mL}^{-1}$, which far exceeds the amount used in conventional SERS biological imaging experiments. As shown in Fig. $6 \mathrm{a}, \mathrm{Ti}_{3} \mathrm{C}_{2}$ monolayers induced no cellular mortality at such high concentration of 
a

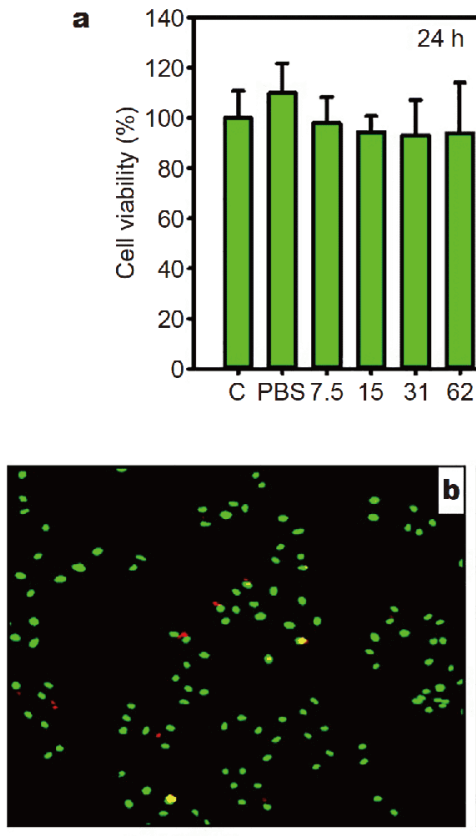

Control
$4 \mathrm{~h}$

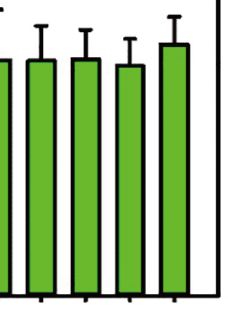

Concentration of $\mathrm{Ti}_{3} \mathrm{C}_{2}\left(\mu \mathrm{g} \mathrm{mL}{ }^{-1}\right)$

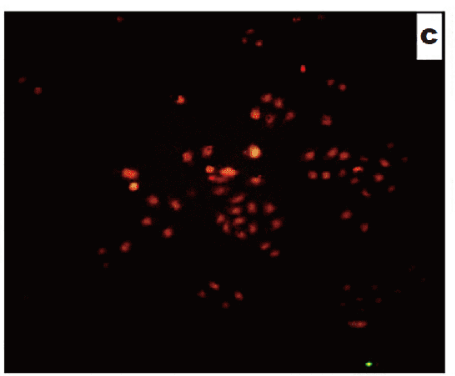

Positive control
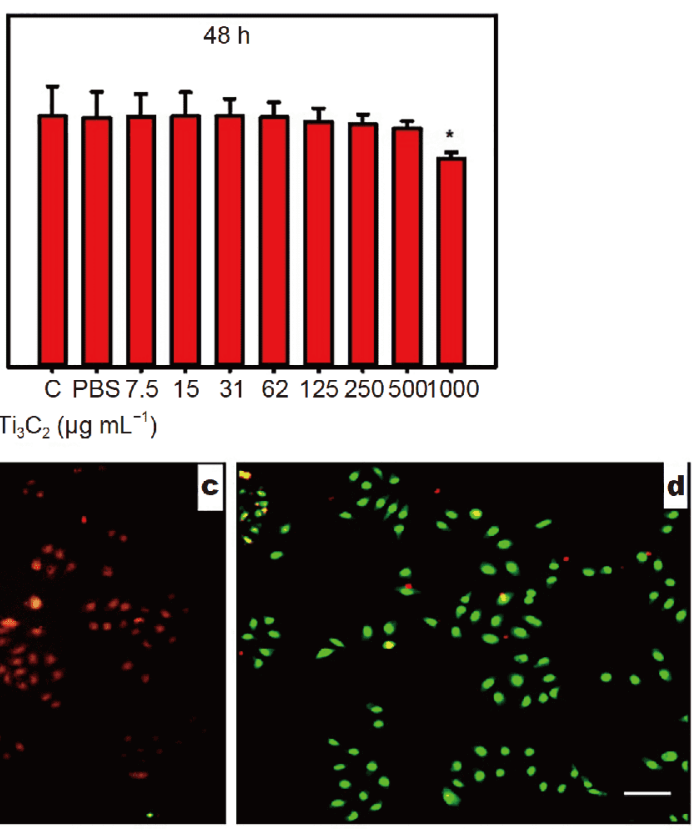

$1000 \mu \mathrm{g} \mathrm{mL}^{-1} \mathrm{Ti}_{3} \mathrm{C}_{2}$

Figure 6 Toxicity of monolayer $\mathrm{Ti}_{3} \mathrm{C}_{2}$ nanosheets. (a) Cell vialibilities after 24 and $48 \mathrm{~h}$ exposure to monolayer $\mathrm{Ti}_{3} \mathrm{C}_{2}$ nanosheets. (b-d) Cell apoptosis in Hela cells exposed to (b) control, (c) positive control $\left(55^{\circ} \mathrm{C}\right.$ for $10 \mathrm{~min}$ ), and (d) $1000 \mu \mathrm{g} \mathrm{mL}^{-1} \mathrm{Ti}_{3} \mathrm{C}_{2}$ nanosheets for $48 \mathrm{~h}$. Live cells were stained with $\mathrm{AO}$ (green), late apoptotic and dead cells were stained EB (red) and early apoptotic cells were both stained by AO and EB (orange). Magnification is $200 \times$ for all panels.

$1000 \mu \mathrm{g} \mathrm{mL}{ }^{-1}$ for $24 \mathrm{~h}$ exposure. Even if extended to $48 \mathrm{~h}$ exposure, the cellular mortality was only $16.9 \pm 2.52 \%$. Furthermore, AO/EB assays revealed that the monolayer $\mathrm{Ti}_{3} \mathrm{C}_{2}$ nanosheets did not trigger apoptosis significantly at the concentration of $1000 \mu \mathrm{g} \mathrm{mL} \mathrm{m}^{-1}$ and upon exposure for $48 \mathrm{~h}$ (Fig. 6b-d). These results indicated that the monolayer $\mathrm{Ti}_{3} \mathrm{C}_{2}$ nanosheets showed considerablely low toxicity at a extremely high concentration for cytotoxicity experiment. Combined with their excellent SERS activity, this low toxicity indicates that the $\mathrm{Ti}_{3} \mathrm{C}_{2}$ monolayer nanosheets have good application prospects in the field of biological tissue detection.

\section{CONCLUSION}

In summary, we have developed an effective chemical exfoliation method for the large-scale synthesis of highly crystalline monolayer $\mathrm{Ti}_{3} \mathrm{C}_{2}$ nanosheets. Due to the unique structure of nucleus-free $2 \mathrm{DEG}$, the $\mathrm{Ti}_{3} \mathrm{C}_{2}$ monolayer has an active surface and shows a strong localized-SPR effect in visible region. These ultrathin $\mathrm{Ti}_{3} \mathrm{C}_{2}$ nanosheets can be easily assembled into flexible SERS substrates with an LOD of $10^{-11} \mathrm{~mol} \mathrm{~L}^{-1}$ and a maximum Raman EF of $3.82 \times 10^{8}$. The experimental and theoretical results show that the ultrasensitive SERS properties of the $\mathrm{Ti}_{3} \mathrm{C}_{2}$ monolayers result from the dual functions of strong lo-
calized-SPR and remarkable interfacial-charge-transfer. Moreover, this new material shows very low cytotoxicity. Current research results show that the low cost quasimetallic $2 \mathrm{D}$ metal carbide is a very promising SERS active material.

Received 27 February 2020; accepted 28 February 2020; published online 25 March 2020

1 Nie S. Probing single molecules and single nanoparticles by surface-enhanced Raman scattering. Science, 1997, 275: 1102-1106

2 Kneipp K, Wang Y, Kneipp H, et al. Single molecule detection using surface-enhanced Raman scattering (SERS). Phys Rev Lett, 1997, 78: 1667-1670

3 Palonpon AF, Ando J, Yamakoshi H, et al. Raman and SERS microscopy for molecular imaging of live cells. Nat Protoc, 2013, 8: 677-692

4 Kneipp J, Kneipp H, Kneipp K. SERS-a single-molecule and nanoscale tool for bioanalytics. Chem Soc Rev, 2008, 37: 1052-1060

5 Li JF, Huang YF, Ding Y, et al. Shell-isolated nanoparticle-enhanced Raman spectroscopy. Nature, 2010, 464: 392-395

6 Mulvihill M, Tao A, Benjauthrit K, et al. Surface-enhanced Raman spectroscopy for trace arsenic detection in contaminated water. Angew Chem, 2008, 120: 6556-6560

7 Wang M, Meng G, Huang Q, et al. CNTs-anchored egg shell membrane decorated with Ag-NPs as cheap but effective SERS substrates. Sci China Mater, 2015, 58: 198-203

8 Duan C, Ren B, Liu H, et al. Flexible SERS active detection from novel Ag nano-necklaces as highly reproducible and ultrasensitive 
tips. Sci China Mater, 2016, 59: 435-443

9 Li J, Liu J, Yang Y, et al. Bifunctional Ag@Pd-Ag nanocubes for highly sensitive monitoring of catalytic reactions by surface-enhanced Raman spectroscopy. J Am Chem Soc, 2015, 137: 70397042

10 Taylor RW, Coulston RJ, Biedermann F, et al. In situ SERS monitoring of photochemistry within a nanojunction reactor. Nano Lett, 2013, 13: 5985-5990

11 Fleischmann M, Hendra PJ, McQuillan AJ. Raman spectra of pyridine adsorbed at a silver electrode. Chem Phys Lett, 1974, 26: 163-166

12 Jeanmaire DL, Van Duyne RP. Surface Raman spectroelectrochemistry. J Electroanal Chem Interfacial Electrochem, 1977, 84: 1-20

13 Moskovits M. Surface roughness and the enhanced intensity of Raman scattering by molecules adsorbed on metals. J Chem Phys, 1978, 69: 4159-4161

14 Lin XM, Cui Y, Xu YH, et al. Surface-enhanced Raman spectroscopy: substrate-related issues. Anal Bioanal Chem, 2009, 394 : 1729-1745

15 Schlücker S. Surface-enhanced Raman spectroscopy: concepts and chemical applications. Angew Chem Int Ed, 2014, 53: 4756-4795

16 Li JF, Zhang YJ, Ding SY, et al. Core-shell nanoparticle-enhanced Raman spectroscopy. Chem Rev, 2017, 117: 5002-5069

17 Zhu C, Meng G, Zheng P, et al. A hierarchically ordered array of silver-nanorod bundles for surface-enhanced Raman scattering detection of phenolic pollutants. Adv Mater, 2016, 28: 4871-4876

18 Quagliano LG. Observation of molecules adsorbed on III-V semiconductor quantum dots by surface-enhanced Raman scattering. J Am Chem Soc, 2004, 126: 7393-7398

19 Qiu B, Xing M, Yi Q, et al. Chiral carbonaceous nanotubes modified with titania nanocrystals: plasmon-free and recyclable SERS sensitivity. Angew Chem Int Ed, 2015, 54: 10643-10647

20 Lin J, Shang Y, Li X, et al. Ultrasensitive SERS detection by defect engineering on single $\mathrm{Cu}_{2} \mathrm{O}$ superstructure particle. Adv Mater, 2017, 29: 1604797

21 Cong S, Yuan Y, Chen Z, et al. Noble metal-comparable SERS enhancement from semiconducting metal oxides by making oxygen vacancies. Nat Commun, 2015, 6: 7800

22 Shan Y, Zheng Z, Liu J, et al. Niobium pentoxide: a promising surface-enhanced Raman scattering active semiconductor substrate. npj Comput Mater, 2017, 3: 11

23 Sun $\mathrm{H}$, Cong S, Zheng Z, et al. Metal-organic frameworks as surface enhanced raman scattering substrates with high tailorability. J Am Chem Soc, 2019, 141: 870-878

24 Wang X, Shi W, Wang S, et al. Two-dimensional amorphous $\mathrm{TiO}_{2}$ nanosheets enabling high-efficiency photoinduced charge transfer for excellent SERS activity. J Am Chem Soc, 2019, 141: 5856-5862

25 Wang X, Shi W, Jin Z, et al. Remarkable SERS activity observed from amorphous $\mathrm{ZnO}$ nanocages. Angew Chem Int Ed, 2017, 56: 9851-9855

26 Yilmaz M, Babur E, Ozdemir M, et al. Nanostructured organic semiconductor films for molecular detection with surface-enhanced Raman spectroscopy. Nat Mater, 2017, 16: 918-924

27 Peng X, Peng L, Wu C, et al. Two dimensional nanomaterials for flexible supercapacitors. Chem Soc Rev, 2014, 43: 3303-3323

28 Wang H, Yang X, Shao W, et al. Ultrathin black phosphorus nanosheets for efficient singlet oxygen generation. J Am Chem Soc, 2015, 137: 11376-11382

29 Zhang H. Ultrathin two-dimensional nanomaterials. ACS Nano,
2015, 9: 9451-9469

30 Xuan J, Wang Z, Chen Y, et al. Organic-base-driven intercalation and delamination for the production of functionalized titanium carbide nanosheets with superior photothermal therapeutic performance. Angew Chem Int Ed, 2016, 55: 14569-14574

31 Xie L, Ling X, Fang Y, et al. Graphene as a substrate to suppress fluorescence in resonance Raman Spectroscopy. J Am Chem Soc, 2009, 131: 9890-9891

32 Muehlethaler C, Considine CR, Menon V, et al. Ultrahigh Raman enhancement on monolayer $\mathrm{MoS}_{2}$. ACS Photonics, 2016, 3: 11641169

33 Soundiraraju B, George BK. Two-dimensional titanium nitride $\left(\mathrm{Ti}_{2} \mathrm{~N}\right)$ MXene: synthesis, characterization, and potential application as surface-enhanced Raman scattering substrate. ACS Nano, 2017, 11: 8892-8900

34 Tao L, Chen $\mathrm{K}$, Chen Z, et al. $1 \mathrm{~T}^{\prime}$ transition metal telluride atomic layers for plasmon-free SERS at femtomolar levels. J Am Chem Soc, 2018, 140: 8696-8704

35 Naguib M, Kurtoglu M, Presser V, et al. Two-dimensional nanocrystals produced by exfoliation of $\mathrm{Ti}_{3} \mathrm{AlC}_{2}$. Adv Mater, 2011, 23: 4248-4253

36 Xie Y, Dall'Agnese Y, Naguib M, et al. Prediction and characterization of MXene nanosheet anodes for non-lithium-ion batteries. ACS Nano, 2014, 8: 9606-9615

37 Lipatov A, Alhabeb M, Lukatskaya MR, et al. Effect of synthesis on quality, electronic properties and environmental stability of individual monolayer $\mathrm{Ti}_{3} \mathrm{C}_{2}$ MXene flakes. Adv Electron Mater, 2016, 2: 1600255

38 Li R, Zhang L, Shi L, et al. MXene $\mathrm{Ti}_{3} \mathrm{C}_{2}$ : an effective 2D light-toheat conversion material. ACS Nano, 2017, 11: 3752-3759

39 Xue Q, Zhang $\mathrm{H}$, Zhu $\mathrm{M}$, et al. Photoluminescent $\mathrm{Ti}_{3} \mathrm{C}_{2}$ MXene quantum dots for multicolor cellular imaging. Adv Mater, 2017, 29: 1604847

40 Yasaei $\mathrm{P}, \mathrm{Tu} \mathrm{Q}, \mathrm{Xu} \mathrm{Y}$, et al. Mapping hot spots at heterogeneities of few-layer $\mathrm{Ti}_{3} \mathrm{C}_{2}$ MXene sheets. ACS Nano, 2019, 13: 3301-3309

41 Yasaei P, Hemmat Z, Foss CJ, et al. Enhanced thermal boundary conductance in few-layer $\mathrm{Ti}_{3} \mathrm{C}_{2}$ MXene with encapsulation. Adv Mater, 2018, 30: 1801629

42 Dong Y, Chertopalov S, maleski K, et al. Saturable absorption in $2 \mathrm{D} \mathrm{Ti}{ }_{3} \mathrm{C}_{2}$ Mxene thin films for passive photonic diodes. Adv Mater, 2018, 30: 1705714

43 Sarycheva A, Makaryan T, Maleski K, et al. Two-dimensional titanium carbide (MXene) as surface-enhanced Raman scattering substrate. J Phys Chem C, 2017, 121: 19983-19988

44 Zrimsek AB, Chiang N, Mattei M, et al. Single-molecule chemistry with surface- and tip-enhanced Raman spectroscopy. Chem Rev, 2017, 117: 7583-7613

45 Hu S, Wang X. Ultrathin nanostructures: smaller size with new phenomena. Chem Soc Rev, 2013, 42: 5577-5594

46 Voiry D, Yang J, Kupferberg J, et al. High-quality graphene via microwave reduction of solution-exfoliated graphene oxide. Science, 2016, 353: 1413-1416

47 Xu S, Zhong G, Chen C, et al. Uniform, scalable, high-temperature microwave shock for nanoparticle synthesis through defect engineering. Matter, 2019, 1: 759-769

48 Ghidiu M, Lukatskaya MR, Zhao MQ, et al. Conductive two-dimensional titanium carbide 'clay' with high volumetric capacitance. Nature, 2014, 516: 78-81

49 Lou Z, Chen Q, Zhang Y, et al. Diamond formation by reduction of carbon dioxide at low temperatures. J Am Chem Soc, 2003, 125: 
9302-9303

50 Li Y, Liao H, Ding Y, et al. Solvothermal elemental direct reaction to $\mathrm{CdE}(\mathrm{E}=\mathrm{S}, \mathrm{Se}, \mathrm{Te})$ semiconductor nanorod. Inorg Chem, 1999, 38: $1382-1387$

51 Zhao S, Li Z, Yang J. Obtaining Two-dimensional electron gas in free space without resorting to electron doping: an electride based design. J Am Chem Soc, 2014, 136: 13313-13318

52 Henkelman G, Arnaldsson A, Jónsson H. A fast and robust algorithm for bader decomposition of charge density. Comput Mater Sci, 2006, 36: 354-360

Acknowledgements This work received financial support from the Science Foundation of Chinese Academy of Inspection and Quarantine (2019JK004), the National Key Research and Development Program of China (2017YFF0210003), and the high performance computing center of Qufu Normal University.

Author contributions $\mathrm{Ye} \mathrm{Y}$ and $\mathrm{Xi} G$ designed and performed the experiments; Yi W calculated the electronic structure; Liu W, Zhou Y and Bai $\mathrm{H}$ discussed partial experimental data; $\mathrm{Li} \mathrm{J}$ and $\mathrm{Xi}$ G wrote the paper. All authors contributed to the general discussion.

Conflict of interest The authors declare that they have no conflict of interest.

Supplementary information Supplementary methods and data are available in the online version of the paper, including Raman enhanced factor calculation, electronic structure calculation, photograph of the dispersion of the monolayer $\mathrm{Ti}_{3} \mathrm{C}_{2}$ nanosheets, XRD patterns of the $\mathrm{Ti}_{3} \mathrm{C}_{2}$ monolayers and $\mathrm{Ti}_{3} \mathrm{AlC}_{2}$, XEDS and XPS spectra of the $\mathrm{Ti}_{3} \mathrm{C}_{2}$ monolayers, UV-Vis absorption spectra of the obtained monolayer $\mathrm{Ti}_{3} \mathrm{C}_{2}$ nanosheets with high crystallinity and low crystallinity, the standard Raman spectrum of R6G reference material, and the crystal structure of $\mathrm{Ti}_{3} \mathrm{C}_{2}$.

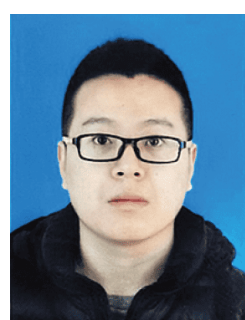

Yuting Ye is currently a MSc candidate in material chemistry under the supervision of Prof. Guangcheng Xi at Chinese Academy of Inspection and Quarantine. His research centers on developing the excellent SERS materials for chemical sensing devices.

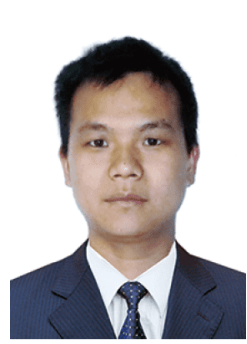

Wencai Yi received his BSc degree in 2013 from Tianjin Normal University. In 2018, he received his $\mathrm{PhD}$ degree from Jilin University, China. Then, he joined Qufu Normal University as a lecturer. His research interests focus on the algorithm of structure prediction, low dimensional gas-sensing materials, SERS and high energy density materials.

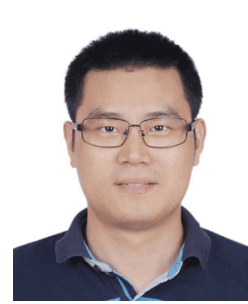

Guangcheng Xi received his BSc degree in 2002 from Fuyang Normal University, China. In 2007, he received his $\mathrm{PhD}$ degree from the University of Science and Technology of China. Then, he joined Chinese Academy of Inspection and Quarantine as an assistant professor. He became an associate professor in 2011 and a full professor in 2017. Currently, his research interests focus on the SERS, chemical sensing, and the nanostructure-based analysis for harmful substances.

高度结晶 $\mathrm{Ti}_{3} \mathrm{C}_{2}$ 单层纳米片的表面增强拉曼散射

叶雨庭 ${ }^{1 \dagger}$, 易文才 ${ }^{2 \dagger}$, 刘伟 ${ }^{1}$, 周云 $^{3}$, 白华 ${ }^{1}$, 李俊芳 ${ }^{1}$, 席广成 ${ }^{{ }^{*}}$

摘要 表面增强拉曼散射(SERS)作为一种优秀的免标记无损检测 技术，已被广泛应用于环境污染物检测、生物组织传感及指纹级 分子分析等领域. 与以贵金属和半导体为代表的传统SERS基底不 同, 本文报道了一种新型的高灵敏SERS基底材料, 即无核二维电子 气 $(2 \mathrm{DEG})$ 结构的 $\mathrm{Ti}_{3} \mathrm{C}_{2}$ 单层纳米片, 其具有高稳定性、生物相容性 和低成本等优点. 我们通过一种化学剥离和微波加热相结合的方 法合成了具有洁净表面的、高度结晶的单层 $\mathrm{Ti}_{3} \mathrm{C}_{2}$ 纳米片. $\mathrm{Ti}_{3} \mathrm{C}_{2}$ 单 层无核 $2 \mathrm{DEG}$ 的独特电子结构提供了理想的无核散射传输通道, 使 单层 $\mathrm{Ti}_{3} \mathrm{C}_{2}$ 纳米片的拉曼增强因子达到了 $3.82 \times 10^{8}$, 其对典型污染 物的检出限高达 $10^{-11} \mathrm{~mol} \mathrm{~L}^{-1}$. 初步的毒理学实验表明, 该物质的 细胞毒性非常低. 考虑到碳化物纳米片合成简单、良好的生物相 容性、低成本以及高的化学稳定性, $\mathrm{Ti}_{3} \mathrm{C}_{2}$ 单层对于设计和制造具 有超高灵敏度的柔性SERS衬底具有很好的应用前景. 